\section{Should Chemoradiotherapy Be Used in Node-Negative Esophageal or Gastric Adenocarcinoma?}

\section{TO THE EDITORS:}

We agree with Drs. Hotenrott and Ziogas that the role and timing of chemotherapy and radiation for patients with advanced disease in the esophagus and stomach needs further clarification. ${ }^{1}$ Our retrospective study attempted to answer this question by analyzing 3378 patients treated in the state of Florida between 1998 and 2002. This data set is complete and allows for patient comorbidities. ${ }^{2,3} \mathrm{We}$ demonstrated a significant benefit for neoadjuvant or adjuvant therapy for patients with regional (node positive) disease. Similar analysis of node-negative disease, however, did not reveal a benefit.

Although our data do not demonstrate a benefit for nodenegative disease, such a benefit is certainly possible; however, our study was underpowered to detect this. In addition, the possibility of downstaging among node-negative patients after neoadjuvant chemotherapy may be an additional confounder. ${ }^{4,5}$

We look forward to the completion and reporting of the CRITICS trial. Yet the possibility of insufficient power for detecting node-negative disease may result in this question remaining unanswered. We nonetheless agree that patients with node-positive adenocarcinoma of the esophagus or stomach benefit from chemotherapy. We also think that the potential benefit in node-negative patients is smaller, if any. Patients should be counseled about these points in the management of these diseases.

\section{Naveenraj L. Solomon, and Leonidas G. Koniaris}

Department of Surgical Oncology, Dewitt Daughtry Family Department of Surgery, University of Miami School of Medicine, Miami, FL

e-mail:nsolomon@med.miami.edu

Published Online: 9 March 2010

(C) Society of Surgical Oncology 2010

\section{REFERENCES}

1. Solomon NL, Cheung MC, Byrne MM, et al. Does chemoradiotherapy improve outcomes for surgically resected adenocarcinoma of the stomach or esophagus? Ann Surg Oncol. 2010;17:98-108.

2. Cheung MC, Koniaris LG, Perez EA, et al. Impact of hospital volume on surgical outcome for head and neck cancer. Ann Surg Oncol. 2009;16:1001-9.

3. Cheung MC, Hamilton K, Sherman R, et al. Impact of teaching facility status and high-volume centers on outcomes for lung cancer resection: an examination of 13,469 surgical patients. Ann Surg Oncol. 2009;16:3-13.

4. Leers JM, Ayazi S, Hagen JA, et al. Survival in lymph node negative adenocarcinoma of the esophagus after R0 resection with and without neoadjuvant therapy: evidence for downstaging of $\mathrm{N}$ status. J Am Coll Surg. 2009;208:553-6.

5. Rice TW, Blackstone EH, Adelstein DJ, et al. N1 esophageal carcinoma: the importance of staging and downstaging. $J$ Thorac Cardiovasc Surg. 2001;121:454-64. 